\title{
A review of leptospirosis in Malaysia.
}

\begin{abstract}
This paper reviews the literature on leptospirosis in Malaysia from its first description in 1928 until the present day. Most of the early reports were on investigations of leptospirosis in wildlife and man and up-to-date, thirty-seven leptospiral serovars from thirteen serogroups have been bacteriologically identified. The thirteen serogroups are: Australis, Autumnalis Bataviae, Canicola, Celledoni, Grippotyphosa, Hebdomadis, Icterohaemorrhagiae, Javanica, Pomona, Pyrogenes, Sejroe and Tarassovi. Rats have been ascribed as the principal maintenance host of leptospires in Malaysia. However, serovars from the Pomona, Pyrogenes and Sejroe serogroups have yet to be isolated from rats. It is considered that the majority of leptospirosis cases in man were due to association of man with an environment where rats were plentiful. Recent investigations on domestic animals disclosed a high prevalence of infection in cattle and pigs and they were suspected as being the maintenance host for serovar hardjo and pomona respectively. There is ample scope for research in leptospirosis, particularly in the epidemiology and control of the disease in domestic animals. The strategy to control the infection in domestic animals and man in Malaysia is bound to be different from that of the temperate countries, basically due to the presence of a large number of leptospiral serovars in wildlife, further confounded by geographical and financial constraints
\end{abstract}

Keyword: Animal; Animal disease; Classification; Domestic animal; Human; Isolation and purification; Leptospira; Leptospirosis; Malaysia; Microbiology; Review. 